EVIDENCE BASED PUBLIC HEALTH POLICY AND PRACTICE

\title{
Environmental risks in the developing world: exposure indicators for evaluating interventions, programmes, and policies
}

\author{
Majid Ezzati, Jürg Utzinger, Sandy Cairncross, Aaron J Cohen, Burton H Singer
}

J Epidemiol Community Health 2005;59:15-22. doi: 10.1136/jech.2003.019471

See end of article for authors' affiliations

Correspondence to: Dr M Ezzati, Harvard School of Public Health, 665 Huntington Avenue, Boston, MA, 02115, USA; mezzati@hsph.harvard. edu

Accepted for publication 6 May 2004
Background: Monitoring and empirical evaluation are essential components of evidence based public health policies and programmes. Consequently, there is a growing interest in monitoring of, and indicators for, major environmental health risks, particularly in the developing world. Current large scale data collection efforts are generally disconnected from micro-scale studies in health sciences, which in turn have insufficiently investigated the behavioural and socioeconomic factors that influence exposure.

Study design: A basic framework is proposed for development of indicators of exposure to environmental health risks that would facilitate the (a) assessment of the health effects of risk factors, (b) design and evaluation of interventions and programmes to deliver the interventions, and (c) appraisal and quantification of inequalities in health effects of risk factors, and benefits of intervention programmes and policies. Specific emphasis is put on the features of environmental risks that should guide the choice of indicators, in particular the interactions of technology, the environment, and human behaviour in determining exposure. The indicators are divided into four categories: (a) access and infrastructure, (b) technology, (c) agents and vectors, and (d) behaviour. The study used water and sanitation, indoor air pollution from solid fuels, urban ambient air pollution, and malaria as illustrative examples for this framework.

Conclusions: Organised and systematic indicator selection and monitoring can provide an evidence base for design and implementation of more effective and equitable technological interventions, delivery programmes, and policies for environmental health risks in resource poor settings.
$\mathrm{R}$ educing environmental health risks in the developing world form an integral part of the overall efforts for improving global health. ${ }^{12}$ As a result, there is growing interest in measuring and monitoring population exposure to major environmental risks and assessment of their health effects, because focusing on risk factors is key for disease prevention..$^{3-6}$ Most monitoring efforts in developing countries have used, and will probably continue to use because of cost, aggregate level data sources such as sample surveys of large populations at the national or sub-national level (for example, demographic and health surveys, DHS). The environmental components of these surveys however have generally been based on "survey convenience" and disconnected from micro-scale studies in environmental health sciences. Consequently, routine population surveys currently provide limited information on details of exposure to environmental risks, which is determined by multiple technological, environmental, and behavioural factors. Epidemiological studies of environmental health, on the other hand, have generally focused on single variable physical and biological measures of risk, and have insufficiently investigated the behavioural and socioeconomic factors that influence exposure to environmental risks.

Reliable and consistent analyses of exposure to environmental risks, and their technological and behavioural determinants, are key for designing interventions, especially in resource poor settings. Furthermore, successful implementation of programmes to disseminate technologies requires examining their socioeconomic dimensions such as technology access, infrastructure, and user behaviour. ${ }^{7}$ In this paper we describe a basic framework for selection of indicators for environmental health risks, which is based on the interactions of the technological, environmental, socioeconomic, and behavioural determinants of risk, using examples from important environmental risks in the developing world. We argue that selected in-depth studies should empirically estimate the contributions of technological, environmental, and behavioural determinants to exposure and to health outcomes. Routine monitoring activities, such as household surveys, can then collect data on more distal indicators selected and quantified based on such in-depth studies at considerably lower cost and effort.

\section{A BASIC FRAMEWORK FOR EXPOSURE TO ENVIRONMENTAL RISKS}

Figure 1 depicts a generic version of a multi-layer "causal

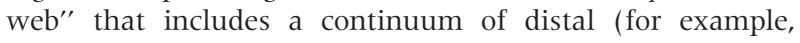
socioeconomic and demographic), proximal (for example, technological, environmental, or behavioural), and physiological and pathophysiological causes of disease. ${ }^{89}$ For example, income and education, irrigation and waste disposal infrastructure, access to clean water and improved sanitation, hygiene behaviour, nutritional status, and the presence of specific pathogens in drinking water or food may all be underlying risk factors for diarrhoeal diseases. ${ }^{10}{ }^{11}$ Similarly, automotive technology and transportation infrastructure, the presence and concentration of lead in petroleum, lead emissions, and blood or bone lead levels are all risk factors for lead induced cognitive effects. ${ }^{12}{ }^{13}$

In many common applications, indicators for which data are available have been used as proxies for "environmental factors" defined broadly (see table 1 in Ezzati et $a l^{5}$ ). At the same time, as schematically shown in figure 1 , a central feature of environmental risks is that exposure itself is determined by multiple technological, environmental, and behavioural factors. As we describe below, measuring and 


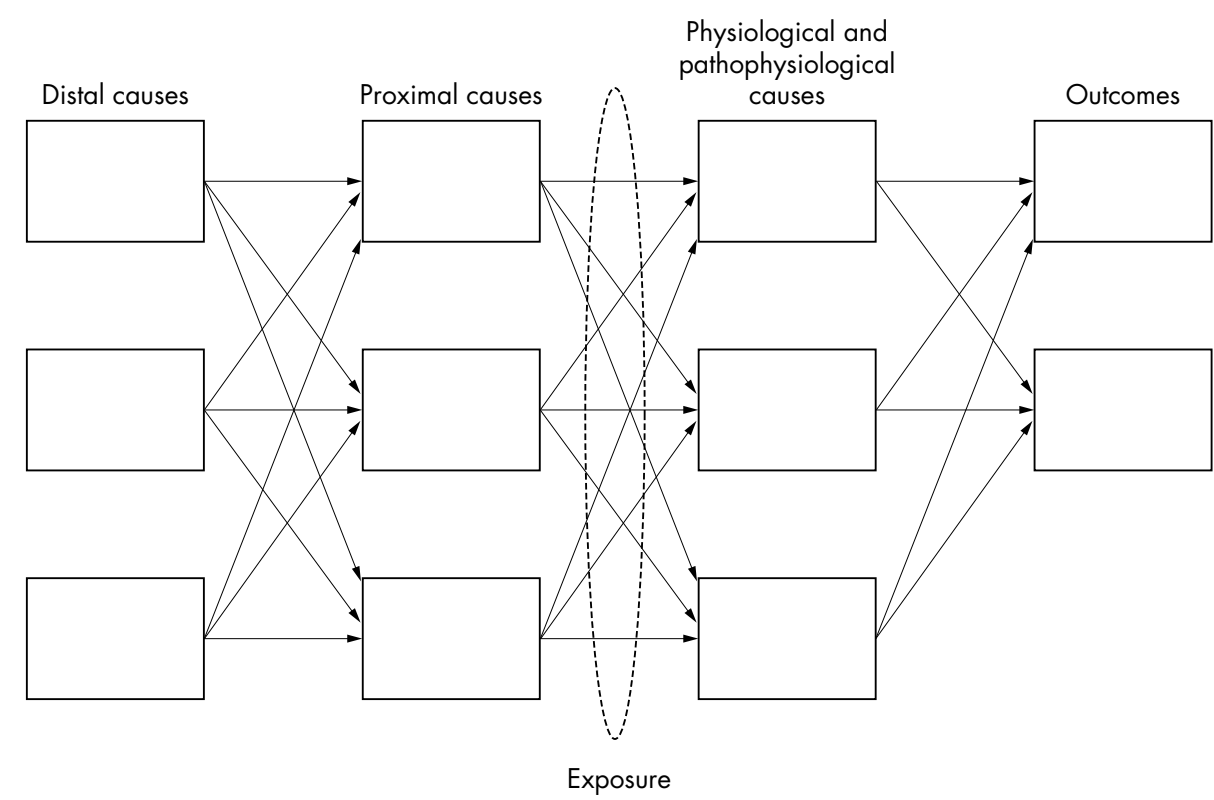

Figure 1 A simplified "causal web" illustrating various levels of disease causality, adapted to environmental risks. There may also be relations between the presence or level of one factor and the hazard associated with another factor (effect modification) (for example, benefits of a clean water source may depend on hygiene behaviour). Feedbacks from outcomes to preceding layers may also exist (for example, individuals or societies may modify their risk behaviour based on health outcomes). In addition to those factors depicted in figure 1, individual or population level variations in susceptibility and access to diagnosis and treatment are also determinants of health outcomes. ${ }^{814}$

monitoring these multiple factors provides a number of benefits for interventions and public health programmes. Therefore, in addition to describing a basic framework for environmental exposure monitoring, this paper contributes to the literature on health indicators by extending the broad concept of "environment" to include multiple dimensions, all with social and policy determinants and measurable health outcomes. $†$

\section{GOALS OF ENVIRONMENTAL RISK INDICATORS}

Public health researchers and practitioners would have at least three important purposes for using indicators of exposure to environmental risks:

\section{(1) Assessment and quantification of population health effects}

The health effect quantification ability has often been phrased as indicator "validity". ${ }^{16}{ }^{17}$ Few indicators can however be dichotomously classified as "valid" or "invalid". Rather, indicators that are more distant from the health outcome may not fully characterise the distributions of exposure and hazard in the population by themselves, because exposure results from the interactions of multiple factors (fig 1), which exhibit heterogeneity within and between populations. ${ }^{18}$ Therefore, the ability of an indicator to predict health effects (that is, its "validity") improves with increasing proximity to a health outcome. The actual measurements of exposure/dose of a pollutant (or mixture of pollutants) and their biological markers (for example, blood or bone lead levels) become the preferable indicator for quantifying disease consequences.

\section{(2) Design and evaluation of interventions}

In addition to estimating the efficacy and/or community effectiveness of an existing intervention, characterising the determinants of exposure can assist in designing new interventions. This purpose is arguably more important in the

† Similar issues exist in the context of nutritional epidemiology, resulting in the use of indicators like blood pressure or lipids and body mass index to represent more complex exposures such as diet, energy intake, and physical activity. Some physiological indicators have been successfully related to more distal factors (for example, blood pressure and salt intake $^{15}$. context of developing world environmental health challenges, where the number of efficacious or cost effective interventions may be limited. For example, emissions from open biomass stoves fluctuate over short time intervals, with emission peaks occurring when fuel is added or moved, the stove is lit, the cooking pot is placed on or removed from the fire, or food is stirred ${ }^{19} 20$ (fig 2A). Because household members who cook-typically women-are closest to the stove at such times, peak emissions contribute significantly to the exposure of female household members (fig 2B). ${ }^{20}$ With such exposure patterns, people who cook gain disproportionately small benefits from improved housing ventilation compared with those who are further away from the stove. ${ }^{21}{ }^{22}$ Interventions using cleaner fuels or stoves that reduce peak emissions, on the other hand, would provide comparably larger benefits to female household members. ${ }^{21}$ In contrast with direct inhalation during cooking described above, bioaccumulation of trace elements (for example arsenic and fluorine) in food dried and stored over the stove for long durations is an important route of exposure to these pollutants in parts of China (figs $3 \mathrm{~A}$ and $3 \mathrm{~B}$ ). ${ }^{23}$ In this case, alternative food drying techniques and behavioural change (for example, washing food before consumption) can reduce exposure and associated health effects, like arsenic poisoning and dental or skeletal fluorosis.

Similarly, malaria transmission can be reduced or interrupted by eliminating mosquito breeding sites that are in close proximity to human habitations, ${ }^{25}$ by locating human settlements at an appropriate distance from the main transmission foci (fig 4A), ${ }^{26}$ or changes in housing designs (for example, mosquito proofing by means of house screening, closure of eaves in houses, and installations of ceilings) (fig 4B). ${ }^{27} 28$

\section{(3) Appraisal and quantification of inequalities in exposures and health effects}

The poor or marginalised groups in most societies simultaneously have higher exposure to multiple environmental risk factors and are also more susceptible to the their hazards. ${ }^{1429}{ }^{30}$ Concentrations of various pollutants in ambient air or distribution of blood lead level in relation to different neighbourhoods and social groups (based on factors like income and race) are examples of indicators that are better representation of the equity aspects than aggregate use 

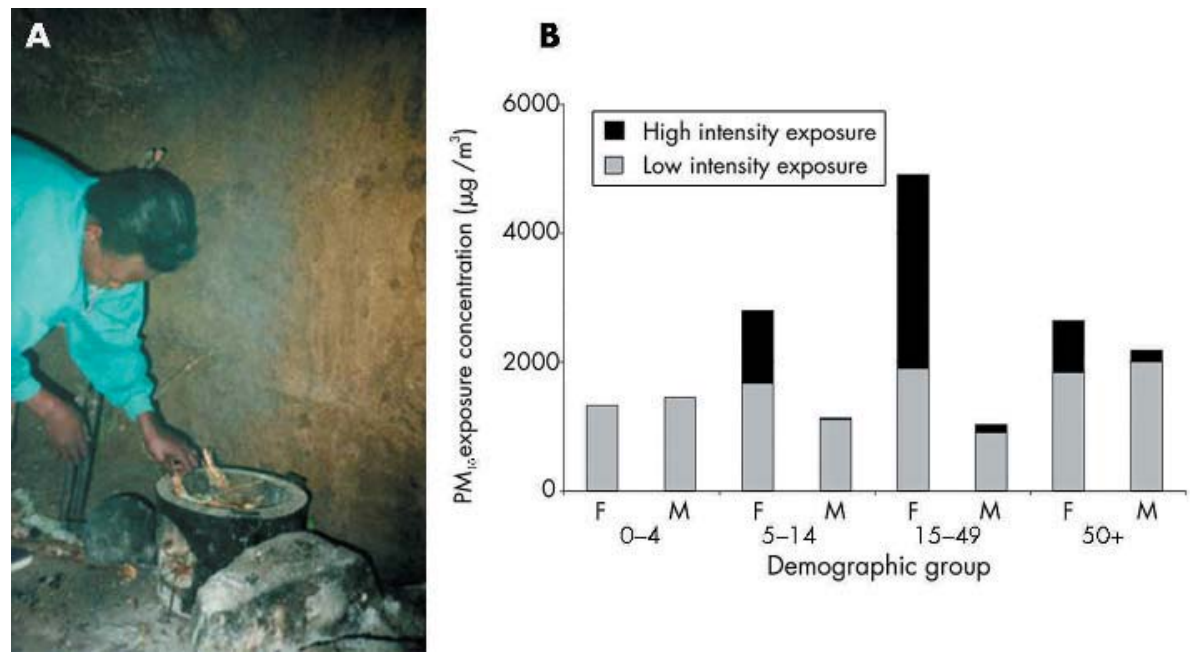

Figure 2 (A) In central Kenya, household members who cook are exposed to episodes of high pollution when they work directly above the fire. (B) For each demographic group the total height of the column is the group's average exposure concentration, divided into average for high and low intensity components. High intensity component is a result of exposure to peak emissions when household members are close to the stove (figure from Ezzati et $a^{20}$ ).

of average urban air pollution or lead in petroleum, which are nevertheless useful to assess the effectiveness of interventions and regulatory programmes. ${ }^{31} 32$

\section{MULTIPLE INDICATORS FOR EXPOSURE TO ENVIRONMENTAL HEALTH RISKS}

While the validity of exposure indicators as predictors of hazards often improves with increasing proximity to health outcomes (for example, blood lead level as an indicator of damage to cognitive function; goal 1 above), physiological indicators alone do not permit measuring the contributions of more distal factors to exposure. This would in turn hamper the design of new and potentially more effective interventions, which may be based on factors such as technology and behaviour (goal 2 above). The multiplicity of analytical and policy/programmatic goals described above should therefore motivate careful selection of environmental health indicators that relate environmental monitoring to exposure biomarkers on the one hand (for health effect assessment), and to technology and behaviour on the other (for designing interventions).

In the following sections we provide a summary of exposure mechanisms for several environmental risk factors that are of particular relevance in the developing world. Table 1 provides examples of indicators. The current availability of studies on multiple exposure determinants varies, being most abundant for water and sanitation, possibly due to the longer history of research on this topic. For each risk factor, references to studies that present the relevant research are also provided.

We divide the indicators into four categories: (a) access and infrastructure, (b) technology, (c) behaviour, and (d) agents and vectors. This classification provides an approximate mapping to various forms of programmes and policies. Access and infrastructure indicators permit assessing the feasibility and cost for increased coverage of technological interventions, which rely on delivery infrastructure. ${ }^{33}$ Access and infrastructure indicators would also illustrate whether the inequalities in exposure are a result of lack of resources at the level of households and individuals, or whether they are caused by absence of broader infrastructure, often not modifiable by household level decisions, and hence requiring public policy action (figs 5A and 5B) ${ }^{34}$ If technology availability is the main determinant of risk exposure, policies that encourage research and development of more effective or less costly technologies are needed. Including behaviour as a category of indicators acknowledges the critical interface between technology and behaviour in determining not only whether a technological intervention is used but also how it is used. Both factors have important implications for the effectiveness of a technology in reducing exposure, ${ }^{75} 36$ and show the role of behavioural interventions. Finally, agents and vectors are not directly modifiable by policies, but are important indicators of hazard, and of success of technological and behavioural interventions. Data on agents and vectors cannot generally be collected in large scale surveys. Data on agents and vectors in selected studies nevertheless facilitate quantifying the role of other exposure indicators.

Multiple indicator categories also assist in identifying "primary" and "secondary" exposure determinants and interventions, with the former affecting several exposure routes simultaneously. For example, in the case of indoor air pollution, the relevance of better ventilated houses (secondary) is determined by the presence or absence of clean fuels (primary). ${ }^{35}$ In the case of water and sanitation, safe excreta disposal and hand washing with soap can interrupt several routes of oral-faecal transmission. ${ }^{11}$ For malaria, effective control through environmental management reduces the pressure on other interventions such as insecticide treated nets or antimalarial drugs. ${ }^{25}$ Where primary exposure routes have been investigated, data needs on secondary exposure routes may be reduced.

\section{Water, sanitation, and hygiene}

The water-borne and water-washed distinction of White et $a l^{38}$ and subsequent analyses ${ }^{11}{ }^{18}{ }^{34}{ }^{39-41}$ have shown that while disease may be transmitted by drinking water containing pathogens, faecal-oral disease transmission may also be reduced or interrupted with increased access to water coupled with domestic hygiene. Quantity of water used, especially at low current consumption levels, depends on water source, the distance of the water source from the household (with a nonlinear relation), and hygiene behaviour. Poor or absent sanitation may increase faecal-oral transmission by contaminating water sources (that is, increasing water-borne transmission), contaminating hands or food (water-scarce diseases), or increasing potential transmission by flies. ${ }^{42} 43$ The impact of excreta disposal is likely to be greatest in crowded urban and peri-urban areas where it prevents faecal contamination of residential environments.

\section{Indoor air pollution from solid fuels}

Hundreds of harmful substances are emitted during the burning of biomass or coal in the form of gases, liquids (suspended droplets), or solids (suspended particulates), in particularly large quantities when burned in open or poorly ventilated stoves. These pollutants include carbon monoxide, 


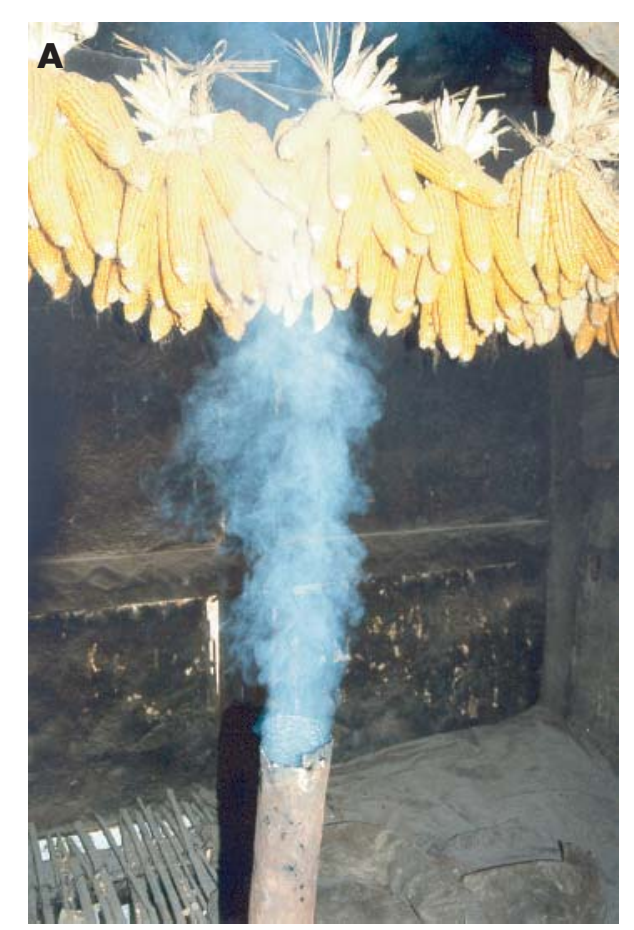

B

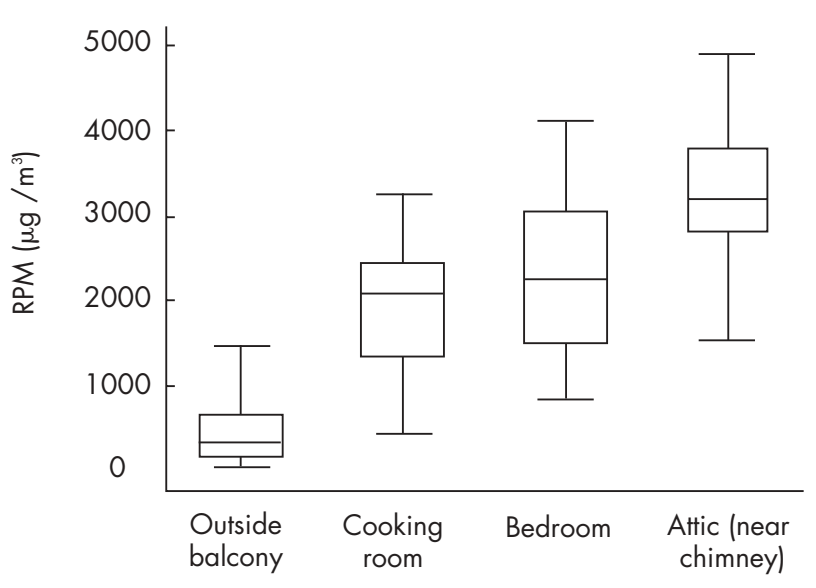

Figure 3 (A) An important route of exposure to fluorine and arsenic from stove use in southern China is bioaccumulation in food (corn and chilli) (B) which are dried near a chimney where pollution levels are highest ${ }^{23}$ (fig from $\mathrm{He}$ et $\mathrm{a}^{24}$ ). RPM, respirable particles.

nitrogen dioxide, particles in the inhalable range $(<10 \mu \mathrm{m}$ in aerodynamic diameter), and other organic matter (predominantly composed of polycyclic aromatic hydrocarbons and other volatile organic compounds such as benzene and formaldehyde). ${ }^{44-46}$ Combustion of coal in addition to the above pollutants may release oxides of sulphur, arsenic, and fluoride. ${ }^{23}$ The concentrations of different pollutants at locations inside the house depend on energy technology (stove and fuel combination), house design (for example, the size and construction materials of the house, the arrangement of rooms, and the number of windows), ${ }^{20} 22$ and stove use behaviour (for example, whether fuel is dried before combustion). In addition to pollution levels, exposure depends on time activity budgets of individual household members (for example, time spent inside or near the stove and direct participation in cooking tasks). ${ }^{20}{ }^{22}$ Whether energy is used for cooking or heating is also an important determinant of exposure.
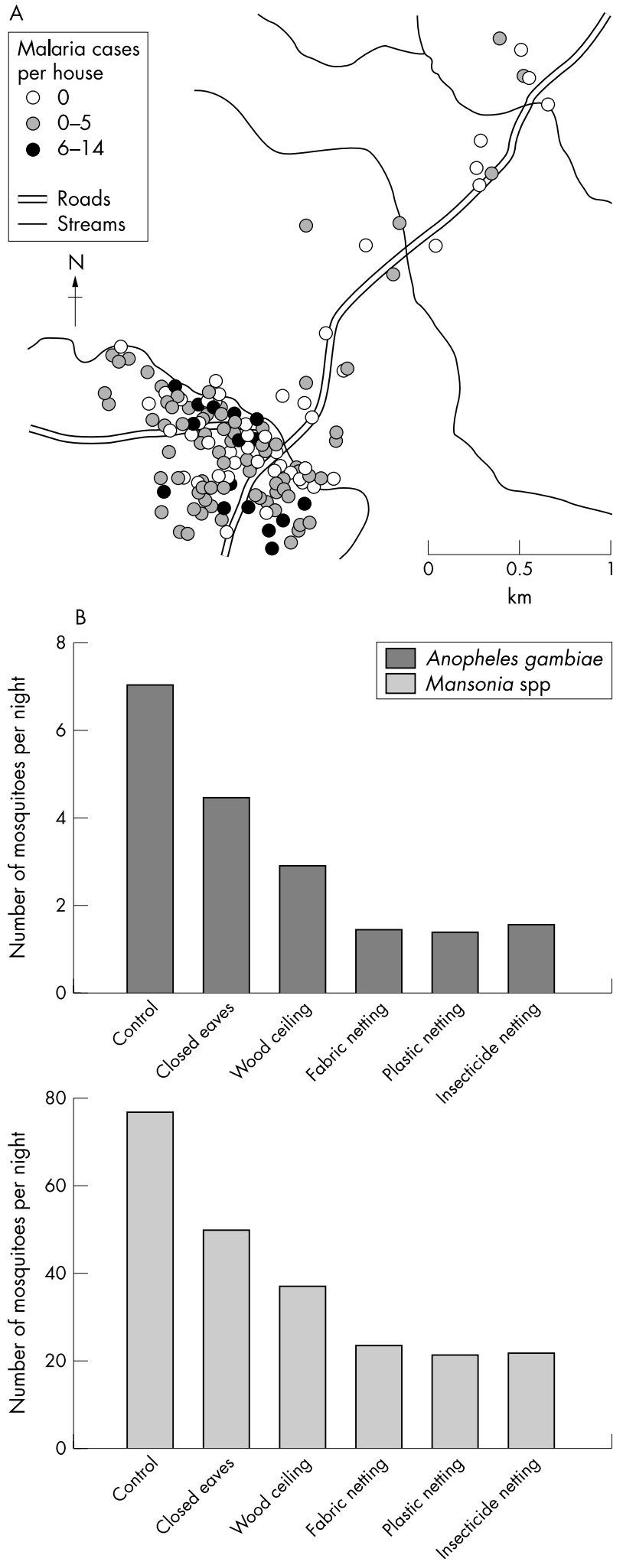

Figure 4 (A) Distance to mosquito breeding sites (figure from Carter et $a^{P^{6}}$ ) and $(B)$ housing characteristics (figure from Lindsay et $a^{P^{7}}$ ) are important determinants and indicators of malaria risk.

Cooking is often done in shorter time intervals and possibly in confined areas, with a subset of household members consistently close to the source of pollution. In contrast, heating by definition entails longer hours of energy use for a larger area, and comparatively similar distance to the energy source for most household members. 


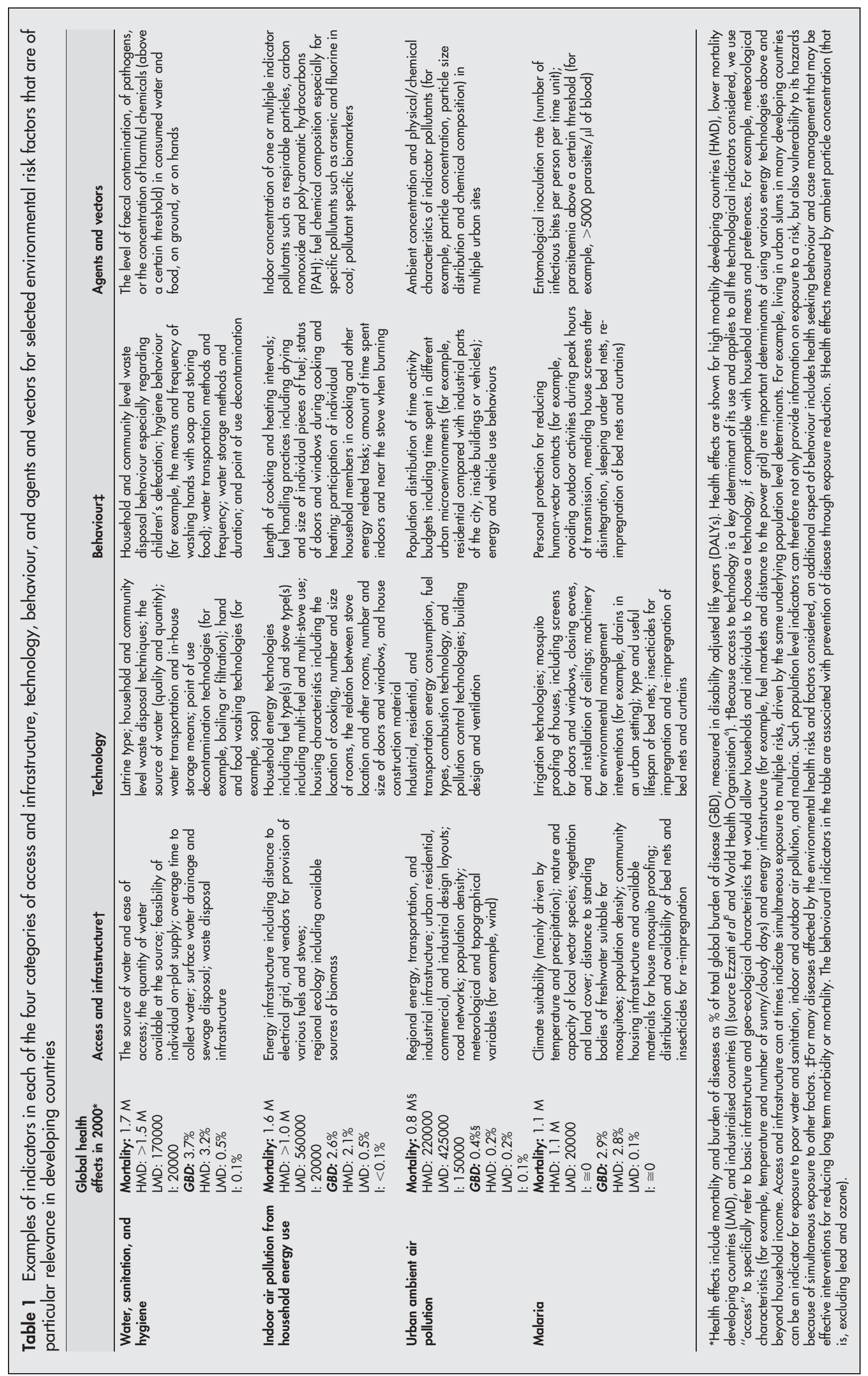



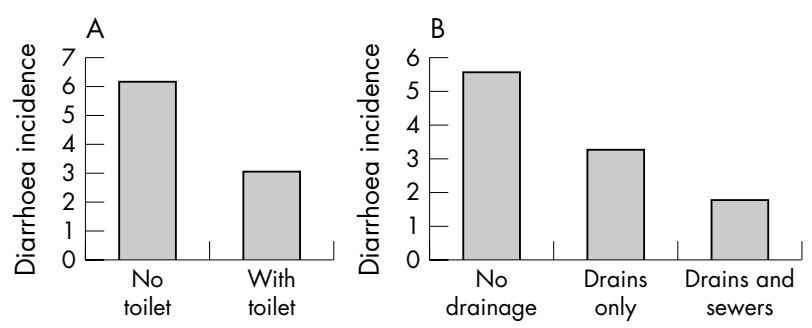

Figure 5 Impact on diarrhoeal disease (A) of toilet technology installed at the individual household level (domestic domain), and (B) of sanitation infrastructure serving the community as a whole (public domain) (data from Moraes et $a^{\beta 7}$ ).

\section{Urban ambient air pollution}

Although urban ambient air pollution has been commonly defined at the level of a city in most epidemiological studies, recent research has illustrated the variation of exposure to this risk and the associated health effects in considerably smaller microenvironments. ${ }^{47-51}$ This variability occurs because: (1) the ambient concentrations, composition, and dispersion of pollutants depend on the type and location of pollution source(s) (for example, use of diesel fuels, or mobile or stationary sources), meteorological factors (for example, wind direction and speed), and urban physical characteristics, (2) indoor concentrations in buildings and vehicles as a result of ambient pollution depend on the locations, type and structure of indoor environments, and (3) individuals and groups spend various amounts of time in different indoor and outdoor urban microenvironments because of the location of residential neighbourhoods and occupational and commercial activities. ${ }^{52}$ Exposure patterns may also differ by pollutant type. For example, fine particles $\left(\mathrm{PM}_{2.5}\right)$ and ozone tend to be more homogenously distributed over large urban or regional areas than ultrafine particles, nitrogen dioxide, and polycyclic aromatic hydrocarbons (PAH) emitted from mobile sources. ${ }^{47}$

Vector borne diseases (for example, malaria)

Malaria transmission exhibits considerable spatial and temporal heterogeneity, largely driven by the specific local

\section{Key points}

- Exposure to environmental risks is determined by multiple technological, environmental, and behavioural factors. Examples are provided from a number of key environmental health issues in the developing world including water and sanitation, indoor air pollution from solid fuels, urban ambient air pollution, and malaria.

- Monitoring multiple exposure determinants would permit both better quantification of health effects of risk factors, and design of more effective interventions. Such integration of data gathering and analysis is possible but requires participation from different disciplines in the physical, social, and health sciences.

- Dividing indicators of exposure to environmental risk into four categories of access and infrastructure, technology, behaviour, and agents and vectors would facilitate assessing whether the obstacles to intervention are attributable to technology, behavioural factors, or lack of infrastructure. This will in turn identify the type of policies and programmes that can be most effective. ecological and environmental characteristics. The single most common feature for disease transmission across endemic settings is the presence and extent of freshwater bodies, and sometimes brackish water sources. The aquatic habitats used by mosquitoes for laying eggs are also highly species specific, which implies that only those sites that support breeding by key malaria vectors need to be controlled..$^{53}$ In addition to controlling mosquito breeding sites, ${ }^{25}$ malaria risk can be lowered significantly by reducing the contact between humans and mosquitoes. High efficacy can be achieved by the design and implementation of protective housing (for example, mosquito proofing by house screening) ${ }^{27}$ and personal protection (for example, sleeping under insecticide treated nets ${ }^{54}$ ).

\section{DISCUSSION}

Above and beyond estimating total health effects, reliable and consistent analyses of exposure to environmental risks are essential for designing technologies and programmes to improve health conditions especially in resource poor settings. Successful implementation of such programmes further requires examining the technological and environmental determinants of exposure in relation to factors such as access, infrastructure, and behaviour. We have presented a basic framework that distinguishes environmental risk factors and their determinants in multiple layers-distal (for example, socioeconomic), proximal (for example, technological, environmental, and behavioural), and physiological (for example, biomarkers)—while representing them as a linked network of cause and effect. To investigate the multiple public health goals of monitoring, selected in-depth studies should empirically estimate the contributions of technological, environmental, and behavioural determinants to exposure and to health outcomes. While an ambitious goal, such indepth studies can be implemented at comparatively low cost by adding more detailed environmental, technological, and socioeconomic variables to longitudinal cohort studies (which have detailed measured data on health outcomes and physiological risks) or by increasing the number of measured health, physiological, and environmental variables in demographic surveillance sites (which collect detailed data on demographic, socioeconomic, and some technological and environmental variables). ${ }^{55}$ Routine monitoring activities such as household surveys can then collect data on selected technological, environmental, and behavioural indicators at considerably lower cost and effort.

An additional aspect of environmental health risks is the crucial role of social and political institutions in risk exposure and the design and implementation of specific intervention

\section{Policy implications}

- Evidence based policies and programmes should integrate the physical and technological dimensions of environmental health with their socioeconomic and behavioural ones. This is especially important in the developing world, where most environmental health exposures and interventions are closely linked with broader aspects of social and economic development such as energy, transportation, and agriculture.

- National and international monitoring efforts - for the millennium development goals for example-should include data on intervention access and delivery infrastructure, technology, and behavioural dimensions of environmental health to provide the required evidence base for intervention and programme design. 
programmes and policies. ${ }^{76-58}$ These institutions lie in a range of scales from households (for example, which household members control household income that could be used for the purchase of fuel and stoves) and community (for example, community water and sanitation committees, systemic racism and class bias in land use decisions and housing market dynamics), to regional or national (for example, environmental regulatory agencies), and even trans-national (project funding by multi-lateral aid agencies, investment in technology research and development).

A challenge in designing research on complex systems, such as technology-behaviour-environment-health linkages, has been integrating data collection and analysis of multiple variables that have traditionally been used in multiple science and social science disciplines. For this reason, many epidemiological studies have focused on single, at times opportunistic, indicators for exposure such as source of water or energy. Our understanding of environmental health hazards and interventions has advanced greatly as a result of such studies. At the same time, continuing to use such indicators alone, especially without linking them to a broader range of socioeconomic and behavioural factors that determine their exact form and hazards would limit the design and implementation of intervention technologies, and of programmes to deliver them. The classification of exposure indicators into access and infrastructure, technology, behaviour, and agents and vectors provides an initial step for such an integrated approach, directed towards the design of more effective interventions.

Currently, multiple national, international, and bilateral efforts in monitoring environmental health risks are underway including the living standard measurement survey (LSMS) of the World Bank, the multi-indicator cluster surveys (MICS) of UNICEF, and the demographic and health surveys (DHS) conducted by Macro International. Given the enormous potential uses of such information as evidence base for policies, programmes, and interventions, we suggest coupling such surveys with longitudinal cohort studies or demographic surveillance sites, and coordinating efforts in detailed selection of specific indicators and data collection.

\section{ACKNOWLEDGEMENTS}

The paper has benefited from comments by three anonymous reviewers. We thank S Lindsay for an electronic copy of figure $4 \mathrm{~B}$.

\section{Authors' affiliations}

M Ezzati, Harvard School of Public Health, Boston, USA

J Utzinger, Swiss Tropical Institute, Basel, Switzerland

S Cairncross, London School of Hygiene and Tropical Medicine, London, UK

A J Cohen, Health Effects Institute, Boston, USA

B H Singer, Office of Population Research, Princeton University, Princeton, USA

Funding: this work was sponsored by the National Institute of Aging (Grant PO1-AG17625). Jürg Utzinger was supported by the Swiss National Science Foundation (Project PPOB. 102883).

Conflicts of interest: none declared.

The views expressed in this paper are those of the authors and do not necessarily reflect the views of the Health Effects Institute (HEI) or its sponsors.

\section{REFERENCES}

1 von Schirnding Y. Health in sustainable development: can we rise to the challenge. Lancet 2002;360:632-7.

2 World Health Organisation. Health and environment in sustainable development. Geneva: WHO, 1997.

3 Pruss A, Corvalan C, Pastides H, et al. Methodologic considerations in estimating burden of disease from environmental risk factors at national and global levels. Int J Occup Environ Health 2001;7:58-67.

4 von Schirnding Y. Health in sustainable development planning: the role of indicators. Geneva: World Health Organisation, 2002.
5 Ezzati M, Lopez AD, Rodgers A, et al. Selected major risk factors and global and regional burden of disease. Lancet 2002;360:1347-60.

6 World Health Organisation. World health report 2002: reducing risks, promoting healthy life. Geneva: WHO, 2002.

7 Agarwal B. Diffusion of rural innovations: some analytical issues and the case of wood-burning stoves. World Dev 1983;11:359-76.

8 Mosley WH, Chen LC. An analytical framework for the study of child survival in developing countries. In: Mosley WH, Chen LC, eds. Child survival, supplement to Population and Development Review, vol 10. 1984:25-45.

9 Murray CJL, Ezzati M, Lopez AD, et al. Comparative quantification of health risks: conceptual framework and methodological issues. Popul Health Metr 2003;1:1.

10 Yerushalmy J, Palmer CE. On the methodology of investigations of etiologic factors in chronic diseases. J Chronic Dis 1959;108:27-40.

11 Curtis V, Cairncross S, Yonli R. Domestic hygiene and diarrhoea-pinpointing the problem. Trop Med Int Health 2000;5:22-32.

12 Annest JL, Pirkle JL, Makuc D, et al. Chronological trend in blood lead levels between 1976 and 1980. N Engl J Med 1983;308:1373-7.

13 Needleman HL, Schell A, Bellinger D, et al. The long-term effects of exposure to low doses of lead in childhood. An 11 -year follow-up report. N Engl J Med 1990;322:83-8.

14 Sexton K, Adgate JL. Looking at environmental justice from an environmental health perspective. J Expo Anal Environ Epidemiol 1999:9:3-8.

15 Elliott P, Stamler J, Nichols R, et al. Intersalt revisited: further analyses of 24 hour sodium excretion and blood pressure within and across populations. Intersalt Cooperative Research Group. BMJ 1996;312:1249-53.

16 Eyles J, Furgal C. Indicators in environmental health: identifying and selecting common sets. Can J Public Health 2002;93:S62-7.

17 Pastides $\mathbf{H}$. An epidemiological perspective on environmental health indicators. World Health Stat Q 1995;48:140-3.

18 Kolsky P, Blumenthal U. Environmental health indicators and sanitationrelated disease in developing countries: limitations to the use of routine data sources. World Health Stat Q 1995:48:132-9.

19 Ezzati M, Mbinda BM, Kammen DM. Comparison of emissions and residential exposure from traditional and improved biofuel stoves in rural Kenya. Environ Sci Technol 2000;34:578-83.

20 Ezzati M, Saleh H, Kammen DM. The contributions of emissions and spatial microenvironments to exposure to indoor air pollution from biomass combustion in Kenya. Environ Health Perspect 2000; 108:833-9.

21 Ezzati M, Kammen DM. Evaluating the health benefits of transitions in household energy technology in Kenya. Energy Policy 2002;30:815-26.

22 Balakrishnan K, Sankar S, Parikh J, et al. Daily average exposures to respirable particulate matter from combustion of biomass fuels in rural households of southern India. Environ Health Perspect 2002;1 10:1069-75.

23 Finkelman RB, Belkin HE, Zheng B. Health impacts of domestic coal use in China. Proc Natl Acad Sci USA 1999:96:3427-31.

24 He G, Ying B, Liu J, et al. Household exposure to multiple indoor ir pollutants in China. Environ Sci Technol (in press).

25 Utzinger J, Tozan Y, Doumani F, et al. The economic payoffs of integrated malaria control in the Zambian copperbelt between 1930 and 1950. Trop Med Int Health 2002;7:657-77.

26 Carter R, Mendis KN, Roberts D. Spatial targeting of interventions against malaria. Bull World Health Organ 2000;78:1401-11.

27 Lindsay SW, Jawara M, Paine K, et al. Changes in house design reduce exposure to malaria mosquitoes. Trop Med Int Health 2003:8:512-17.

28 Charlwood JD, Pinto J, Ferrara PR, et al. Raised houses reduce mosquito bites. Malar J 2003;2:45

29 Sexton K, Gong H Jr, Bailar JC 3rd, et al. r pollution health risks: Do class and race matter? Toxicol Ind Health 1993;9:843-78.

30 May J, Norton A. A difficult life: the experiences and perceptions of poverty in South Africa. Soc Indic Res 1997;41:95-18.

31 Perlin SA, Wong D, Sexton K. Residential proximity to industrial sources of air pollution: interrelationships among race, poverty, and age. J Air Waste Manag Assoc 2001;51:406-21.

32 O'Neill MS, Jerrett $M$, Kawachi I, et al. Health, wealth and air pollution: advancing theory and methods. Environ Health Perspect 2003;1 1 1:1861-70.

33 Kahlmeier S, Braun-Fahrlander C. Environmental health indicators in policy evaluation. Eur J Public Health 2004; 14:101-4.

34 Cairncross S, Blumenthal U, Kolsky P, et al. The public and domestic domains in the transmission of disease. Trop Med Int Health 1996;1:27-34.

35 Ezzati M, Kammen DM. The health impacts of exposure to indoor air pollution from solid fuels in developing countries: knowledge, gaps, and data needs. Environ Health Perspect 2002;110:1057-68.

36 Minja H, Schellenberg JA, Mukasa O, et al. Introducing insecticide-treated nets in the Kilombero Valley, Tanzania: the relevance of local knowledge and practice for an information, education and communication (IEC) campaign. Trop Med Int Health $2001 ; 6: 614-23$.

37 Moraes LRS, Cancio JA, Cairncross S, et al. Impact of drainage and sewerage on diarrhea in poor urban areas in Salvador, Brazil. Trans $R$ Soc Trop Med Hyg 2003;97:153-8.

38 White G, Bradley DJ, White AU. Drawers of water: domestic water use in East Africa. Chicago: Chicago University Press, 1972

39 Cairncross $\mathbf{S}$. Health impacts in developing countries: new evidence and new prospects. Journal of the Institution of Water and Environmental Management 1990;4:571-7

40 Cairncross S. Water supply and sanitation: some misconceptions. Trop Med Int Health 2003;8:193-5.

41 Curtis V, Cairncross S. Effect of washing hands with soap on diarrhoea risk in the community: a systematic review. Lancet Infect Dis 2003;3:275-81.

42 Chavasse DC, Shier RP, Murphy OA, et al. Impact of fly control on childhood diarrhoea in Pakistan: community-randomised trial. Lancet 1999;353:22-5. 
43 Emerson PM, Lindsay SW, Walraven GE, et al. Effect of fly control on trachoma and diarrhoea. Lancet 1999;353:1401-3.

44 De Koning HW, Smith KR, Last JM. Biomass fuel combustion and health. Bull World Health Organ 1985;63:11-26.

45 Smith KR. Biofuels, air pollution, and health: a global review. New York: Plenum Press, 1987.

46 Zhang J, Smith KR. Indoor air pollution: formaldehyde and other carbonyls emitted from various cookstoves. Proceedings of indoor air 96: the 7th international conference on indoor air quality and climate, Nagoya, Japan, 1996:85-90.

47 Braver M, Saksena S. Accessible tools for classification of exposure to particles. Chemosphere 2002;49:1151-62.

48 Levy Jl, Houseman EA, Ryan L, et al. Particle concentrations in urban microenvironments. Environ Health Perspect 2000;108:1051-7.

49 Hoek G, Fischer P, Van Den Brandt P, et al. Estimation of long-term average exposure to outdoor air pollution for a cohort study on mortality. J Expo Anal Environ Epidemiol 2001;11:459-69.

50 Hoek G, Brunekreef B, Goldbohm S, et al. Association between mortality and indicators of traffic-related air pollution in the Netherlands: a cohort study. Lancet 2002;360:1203-09.
51 Jerrett $M$, Burnett RT, Kanaroglou $P$, et al. A GIS-environmental justice analysis of particulate air pollution in Hamilton, Canada. Environ Plan $A$ $2001 ; 33: 955-73$

52 Ozkaynak $\mathrm{H}$, Spengler J. The role of outdoor particulate matter in assessing total human exposure. In: Wilson R, Spengler JD, eds. Particles in out air: concentrations and health effects. Cambridge, MA: Harvard University Press, 1996.

53 Bradley DJ. Watson, Swellengrebel and species sanitation: environmental and ecological aspects. Parassitologia 1994;36:137-47.

54 Lengeler $\mathrm{C}$. Insecticide-treated bednets and curtains for preventing malaria. Cochrane Database Sys Rev 2004(2):CD00063.

55 De Savigny D, Binka F. Monitoring future impact on malaria burden in subSaharan Africa. Am J Trop Med Hyg 2004;71(suppl 2):224-31.

56 Gauri V, Khaleghian P. Immunization in developing countries: its political and organizational determinants. World Development 2002;30:2109-32

57 Garfield R. Malaria control in Nicaragua: social and political influences on disease transmission and control activities. Lancet 1999;354:414-18.

58 Scott JC. Seeing like a state: how certain schemes to improve the human condition have failed. New Haven: Yale University Press, 1998.

\section{$\mathrm{ECHO}$}

Declining prevalence of STI in the London sex industry, 1985 to 2002 H Ward, S Day, A Green, K Cooper, J Weber

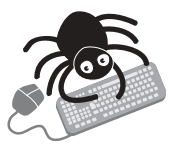

Please visit the Journal of Epidemiology and

Community Health website [www.jech. com] for a link to the full text of this article.
Objectives: To describe major changes in the London sex industry between 1985 and 2002 and assess the implications for sexually transmitted infection (STI) risk.

Method: A descriptive study comparing women who first attended a sex work clinic between 1996 and 2002 and those first attending from 1985 to 1992; a nested case-control study. 1050 female sex workers took part. The setting was a specialist clinical service for sex workers based in a London genitourinary medicine (GUM) clinic, and fieldwork in west London. The main outcome measures were reported condom use and prevalent STI.

Results: Over the period of the study there was a significant increase in the proportion of sex workers not born in the United Kingdom (from 25\% to 63\%, p <0.001), and women entered sex work at an older age (median 24 years compared with 20 years, $\mathrm{p}<0.001$ ). Condom use increased (with the exception of oral sex). There was a significant decline in the proportion of participants reporting a previous STI $(32 \%$ compared with $80 \%, p<0.001)$ and the prevalence of acute STI declined from $25 \%$ to $8 \%(p<0.001)$. Acute STI was associated with younger age, younger age at first sex work, being new to sex work, and inconsistent condom use. In a multivariate analysis unprotected sex with clients was the only significant risk.

Conclusion: Major restructuring of the sex industry, including the shift to a primarily migrant workforce, has been associated with a steep decline in acute STI, undermining popular assumptions that migrant sex workers are central to the ongoing STI epidemic. We attribute the decline in acute STI to an increase in safer sex.

A Sexually Transmitted Infections 2004;80:374-378. 